Artículo científico

Volumen 30(2):497-515. Mayo-agosto, 2019

e-ISSN 2215-3608, doi:10.15517/am.v30i2.34723

https://revistas.ucr.ac.cr/index.php/agromeso/index

\title{
Perfil lipídico en leche de vacas en pastoreo de gramíneas en el trópico seco colombiano $^{1}$
}

\section{Lipid profile in milk of grazing cows in the colombian dry tropics}

\author{
José Edwin Mojica-Rodríguez ${ }^{2}$,Edwin Castro-Rincón ${ }^{3}$, Juan Evangelista Carulla-Fornaguera ${ }^{4}$, \\ Carlos Eduardo Lascano-Aguilar ${ }^{5}$
}

1 Recepción: 18 de octubre, 2018. Aceptación: 6 de diciembre, 2018. Este trabajo formó parte de la agenda de investigación de la Corporación Colombiana de Investigación Agropecuaria (AGROSAVIA) con recursos del Ministerio de Agricultura y Desarrollo Rural, Colombia.

2 Corporación Colombiana de Investigación Agropecuaria (AGROSAVIA). Red de Ganadería y Especies Menores. CI Motilonia. Km 5 vía a Becerril - Agustín Codazzi, Cesarm Colombia. jmojica@agrosavia.co

3 Corporación Colombiana de Investigación Agropecuaria (AGROSAVIA). Red de Ganadería y Especies Menores. CI Obonuco. Km 5 vía a Pasto - Obonuco, Nariño, Colombia. ecastro@agrosavia.co (https://orcid.org/0000-0001-9841-8242).

4 Universidad Nacional de Colombia. Facultad de Medicina Veterinaria y Zootecnia, Sede Bogotá. Bogotá, Colombia. Cra. 45. No. 26 - 85. jecarullaf@unal.edu.co

5 Centro Internacional de Agricultura Tropical (CIAT). Km. 17. Recta Cali - Palmira. Valle del Cauca, Colombia. c.lascano@cgiar.org.co

\section{Resumen}

Introducción. La composición de la grasa en la leche bovina tiene relevancia en la salud humana, donde ácidos grasos poliinsaturados como el ácido linoleico conjugado (ALC c9 t11), tienen efectos positivos (anticarcinogénicos, antidiabetogénico). Existen investigaciones sobre efecto de la alimentación de los bovinos en la calidad de la leche en zonas templadas (por encima de $2200 \mathrm{msnm}$ ), pero pocas en el trópico bajo colombiano (por debajo de $1500 \mathrm{msnm}$ ). Objetivo. El objetivo de este trabajo fue evaluar el efecto de tres gramíneas, Mulato II, Tanzania y Toledo, sobre la producción, composición y perfil lipídico de la leche de vacas gyr x pardo suizo en el primer, segundo y tercer tercio de lactancia. Materiales y métodos. El estudio se llevó a cabo durante mayo y junio de 2013, en el municipio de San Diego, Cesar, Colombia. Se seleccionaron dos grupos de nueve animales (tres vacas en cada tercio de lactancia) y se asignó una vaca de cada tercio de lactancia a cada gramínea en un diseño de cuadrado latino 3 x 3 replicado. Resultados. La producción de leche fue similar $(p>0,05)$ en las gramíneas evaluadas y disminuyó $(p<0,05)$ conforme avanzó la lactancia. La concentración de grasa y proteína en la leche fue mayor $(\mathrm{p}<0,05)$ en Tanzania y Mulato II, aunque en el segundo tercio hubo un mayor $(\mathrm{p}<0,05)$ contenido de ácidos grasos poliinsaturados respectivamente, en comparación con Toledo. El tercio de lactancia no afectó $(\mathrm{p}>0,05)$ la composición de la leche. Se presentó una mayor $(\mathrm{p}<0,05)$ concentración de ácido linoleico conjugado y de ácidos poliinsaturados en la grasa de la leche en vacas alimentadas con los pastos Tanzania y Toledo. Conclusión. Alimentar vacas doble propósito con pastos Tanzania y Toledo podría tener efectos positivos en salud humana, debido al perfil lipídico más saludable de la leche producida.

Palabras clave: ácidos grasos en leche bovina, alimentación animal, forrajes, razas mixtas. 


\begin{abstract}
Introduction. The composition of fat in bovine milk has relevance in human health, where polyunsaturated fatty acids such as conjugated linoleic acid (ALC c9 t11) have positive effects (anticarcinogenic, antidiabetogenic). There are investigations regarding the effect of bovine feeding on milk quality in temperate zones (above 2200 m.a.s.l.), but few in the Colombian low tropics (below 1500 m.a.s.l.). Objetive. The objective of this work was to evaluate the effect of three grasses Mulato II, Tanzania, and Toledo on production, composition, and lipid panel in the milk of Gyr x Brown Swiss cows in the first-second-and three-third of lactation. Materials and methods. The study was conducted from May to June 2013 in the city council of San Diego, Cesar, Colombia. Two groups of nine animals were selected (three cows in each third lactation stage), and one cow was assigned to each grass in a replicated $3 \times 3$ Latin Square design. Results. Milk production was similar $(\mathrm{p}>0.05)$ in evaluated grasses and decreased $(\mathrm{p}<0.05)$ as the lactation advanced. The concentration of milk fat and protein was higher $(\mathrm{p}<0.05)$ in Tanzania and Mulato II, although in the second-third there was a higher content $(\mathrm{p}<0.05)$ of polyunsaturated acids, compared to Toledo. The lactation trimester did not affect $(\mathrm{p}>0.05)$ milk composition. There was higher fed $(\mathrm{p}<0.05)$ concentration of conjugated linoleic acid and polyunsaturated fatty acids in milk fat in cows fed with Tanzania and Toledo forage. Conclusion. Feeding dual-purpose cows with Tanzania and Toledo grasses could have positive effects on human health, due to the healthier lipid panel of the milk produced.
\end{abstract}

Keywords: fatty acids in bovine milk, animal feeding, forage, multiple purpose breeds.

\title{
Introducción
}

En la última década ha habido interés creciente en entender los factores que modifican el perfil lipídico de la leche, debido a la importancia que este tiene sobre la salud humana (Kelly et al., 2008; Benjamin y Spener, 2009; Jutzeler y Colombani, 2010; Dilzer y Park, 2012). A pesar de que existe controversia sobre el efecto de los ácidos grasos (AG) saturados como factores de riesgo en la presentación de enfermedades cardiovasculares (Siri et al., 2010; Soedamah-Muthu et al., 2011; Huth y Park, 2012; Kratz et al., 2013), se acepta que algunos AG poliinsaturados en la leche, como el ácido linoleico conjugado (ALC c9 t11), tienen efectos positivos sobre la salud humana (i.e. anticarcinogénico, antidiabetogénico) (Jutzeler y Colombani, 2010; Dilzer y Park, 2012).

Los isómeros del ácido linoleico conjugado (ALC) se producen en el proceso de biohidrogenación ruminal de los ácidos linoleico (C18:2) y linolénico (C18:3) aportados por los alimentos (Bessa et al., 2000). En la leche bovina se han identificado más de veinticuatro isómeros de ALC; dentro de esos, el c9 t11 y el t7 c9 C18:2, constituyen la mayor proporción (Corl et al., 2001).

En Colombia, en lecherías especializadas de zonas templadas se ha evaluado el efecto de la oferta de forraje sobre la producción y calidad composicional de la leche en vacas Holstein, principalmente con pasto kikuyo $(C$. clandestinus). Se obtuvo un aumento entre 22,4 y $21,8 \%$ en la producción diaria de leche por vaca y entre 14 y $21 \%$ en la concentración de proteína en la leche de vacas Holstein, al pasar de una oferta de 3 a 5 y de 3 a $7 \mathrm{~kg}$ de MS.100 $\mathrm{kg}^{-1}$ de peso vivo (PV), respectivamente (Escobar y Carulla, 2003). Posteriormente, cuando se evaluaron tres ofertas de forraje de pasto kikuyo (2,6, 3,3 y 4,0 kg MS.100 $\left.\mathrm{kg}^{-1} \mathrm{PV}\right)$ con vacas Holstein en primer y segundo tercio de lactancia, Mojica et al. (2009) observaron un incremento lineal en la producción de leche a medida que se incrementó la oferta de forraje en vacas de primer tercio de lactancia. Sin embargo, la calidad composicional de la leche no varió con los niveles de oferta evaluados. En otro estudio, Mendoza et al. (2011) evaluaron el efecto de variaciones diarias de la oferta de pasto kikuyo sobre la producción y calidad composicional de la leche de vacas Holstein en fincas de 


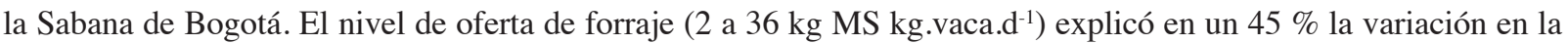
producción diaria de leche observada, pero solo en un $12 \%$ en la variación en la concentración de proteína.

En el sistema bovino de doble propósito en Colombia, se han realizado estudios para evaluar el efecto de especies forrajeras sobre la producción y/o calidad composicional de la leche bovina (Mosquera y Lascano, 1992; Argel et al., 2007; Roncallo et al., 2009). En otros estudios se ha evaluado el efecto de suplementos sobre el perfil lipídico en la leche bovina; por ejemplo, en sistemas silvopastoriles, Mahecha et al. (2008) evaluaron el uso de grasas sobrepasantes, mientras que Prieto-Manrique et al. (2017) evaluaron la utilización de aceite de girasol. Los resultados en estos estudios demostraron efectos positivos (incremento en la concentración de AG insaturados y menor relación de ácidos saturados/insaturados) en el perfil lipídico de la leche; sin embargo, en la revisión realizada no se encontraron estudios sobre efecto de diferentes cultivares de gramíneas bajo pastoreo y sin suplementación, sobre el perfil lipídico en la grasa de la leche bovina en el sistema doble propósito.

En lecherías doble propósito de la microrregión Valle del Cesar, correspondiente al trópico seco de Colombia, el pasto Megathyrsus maximus cv. Tanzania es la gramínea introducida que más se utiliza, y se caracteriza por la alta producción de forraje y el buen valor nutricional (Mojica et al., 2013). Además, las especies del género Brachiaria (i.e. B. brizantha cv. Toledo, Brachiara hibrido cv. Mulato II), han demostrado estar bien adaptadas a las condiciones edafoclimáticas en el trópico seco (CORPOICA, 2013).

El objetivo del presente trabajo fue evaluar el efecto de tres gramíneas, Mulato II, Tanzania y Toledo, sobre la producción, composición y perfil lipídico de la leche de vacas gyr x pardo suizo en el primer, segundo y tercer tercio de lactancia.

\section{Materiales y métodos}

\section{Localización}

El experimento se desarrolló en la Finca San Carlos, ubicada a $9^{\circ} 50^{\prime}$ '19" de latitud norte y $73^{\circ} 22^{\prime}$ '54" de longitud oeste, en el municipio de San Diego en la microrregión Valle del Cesar del Departamento del Cesar, Colombia. En la zona se presenta una temperatura promedio anual de $28,7{ }^{\circ} \mathrm{C}$, humedad relativa de $70 \%$, precipitación anual promedio de $1600 \mathrm{~mm}$ con distribución bimodal en los meses de mayo a junio y de septiembre a diciembre. Los suelos son superficiales a profundos, bien drenados, de fertilidad moderada a alta, característicos de la zona agroecológica Cj (CORPOICA, 2002). El estudio se realizó en época de lluvias durante los meses de mayo (284 mm total de precipitación) y junio (133 mm total de precipitación) del año 2013.

\section{Tratamientos}

Se evaluaron tres cultivares comerciales de gramíneas tropicales bajo pastoreo: Tanzania (Megathyrsus maximus cv. Tanzania) (testigo), Mulato II (Brachiaria híbrido cv. Mulato II) y Toledo (Brachiaria brizantha cv. Toledo). Se utilizaron 6 ha, correspondientes a 2 ha para cada cultivar de pasto, con su respectiva repetición. El área en cada repetición se dividió en dos parcelas de 0,5 ha, donde la primera parcela fue para acostumbramiento (siete días) y la segunda para realizar mediciones en los animales (siete días).

En este estudio el periodo de acostumbramiento fue de siete días se definió para los animales en cada uno de los tratamientos con base en la investigación de Jeffery (1970), quien sugirió un periodo de acostumbramiento de cuatro días mínimo, y del estudio de Stoobs y Sandland (1972), quienes sugirieron un periodo de acostumbramiento entre cuatro a nueve días para evaluar el efecto de forrajes sobre la producción de leche de vacas en pastoreo. Respecto al efecto sobre los ácidos grasos en la leche, Elgersma et al. (2004) demostraron que después de cuatro 
días de transición de una dieta de pasto fresco a una de ensilaje maíz/pasto, se observaron cambios en la mayoría de AG en la grasa de la leche bovina. Al cambiar de una ración totalmente mezclada (TMR, por sus siglas en inglés) a una dieta de forrajes en solo pastoreo, la composición de AG en la grasa de la leche se estabilizaba a los seis días de la transición (Rego et al., 2016). En contraste, cuando el cambio era de una dieta de sólo pastoreo a TMR la mayoría de los AG en la grasa de la leche se estabilizaron entre 14 y 21 días del cambio. Estos estudios indican que un periodo de acostumbramiento de siete días es apropiado para evaluar el efecto de dietas de vacas en pastoreo sobre la producción, composición y concentración de AG en la grasa de la leche.

\section{Establecimiento de las especies y manejo del pastoreo}

El suelo donde se realizó el experimento presentó una estructura franco-arenosa, con pH entre 6,2 a 6,4, materia orgánica de 0,7 a 1,3\%, sin aluminio ni salinidad (Cuadro 1) y con buen drenaje.

Cuadro 1. Análisis de suelo en los lotes experimentales (valores promedio). San Diego, Departamento del Cesar, Colombia. MayoJunio. 2013.

Table 1. Soil analisys in the experimental lots (average values). San Diego, Cesar Department, Colombia. May-June. 2013.

\begin{tabular}{cc}
\hline Componente & Valor \\
\hline pH & 6,2 \\
Conductividad eléctrica $\left(\mathrm{ds} \cdot \mathrm{m}^{-1}\right)$ & 0,99 \\
Materia orgánica $\left(\mathrm{g} \cdot 100 \mathrm{~g}^{-1}\right)$ & 1,1 \\
Calcio $\left(\mathrm{cmol} \cdot \mathrm{kg}^{-1}\right)$ & 19,01 \\
Magnesio $\left(\mathrm{cmol} \cdot \mathrm{kg}^{-1}\right)$ & 1,98 \\
Potasio $\left(\mathrm{cmol} \cdot \mathrm{kg}^{-1}\right)$ & 0,51 \\
Sodio $\left(\mathrm{cmol} \cdot \mathrm{kg}^{-1}\right)$ & $<0,14$ \\
Capacidad de intercambio catiónico efectiva & 21,55 \\
Hierro $\left(\mathrm{mg} \cdot \mathrm{kg}^{-1}\right)$ & 32,65 \\
Fósforo $\left(\mathrm{mg} \cdot \mathrm{kg}^{-1}\right)$ & 142,2 \\
Azufre $\left(\mathrm{mg} \cdot \mathrm{kg}^{-1}\right)$ & 11,5 \\
Manganeso $\left(\mathrm{mg}^{-1} \mathrm{~kg}^{-1}\right)$ & 1,82 \\
Zinc $\left(\mathrm{mg} \cdot \mathrm{kg}^{-1}\right)$ & $<1,0$ \\
Cobre $\left(\mathrm{mg} \cdot \mathrm{kg}^{-1}\right)$ & 3,87 \\
Boro $\left(\mathrm{mg} \cdot \mathrm{kg}^{-1}\right)$ & 0,36 \\
\hline
\end{tabular}

Para la preparación de terreno se realizó un pase de cincel, dos pases de rastra y un pase de rastrillo pulidor. La siembra de las gramíneas se realizó al voleo en forma manual con una densidad de siembra de 8,8 y $5 \mathrm{~kg}$.hapara los cultivares Tanzania, Mulato II (semilla peletizada) y Toledo, respectivamente.

El control de arvenses durante la fase de establecimiento, se realizó en forma manual y con dos aplicaciones de sal dimetilamina del ácido 2,4 diclorofenoxiacético $\left(31 \cdot \mathrm{ha}^{-1}\right)$. Al mes de emergencia de las plántulas, se aplicaron $40 \mathrm{~kg} /$ ha de fosfato diamónico, $25 \mathrm{~kg}$.ha- ${ }^{-1}$ de nitrógeno (urea) y $13 \mathrm{~kg} \cdot \mathrm{ha}^{-1}$ de cloruro de potasio. Un año después del establecimiento, al momento de iniciar el experimento, se realizó un corte de uniformización con guadaña de tractor y se aplicaron $25 \mathrm{~kg} \cdot \mathrm{ha}^{-1}$ de nitrógeno (urea) y $13 \mathrm{~kg}_{\text {. ha }}{ }^{-1}$ de cloruro de potasio. Los potreros con una carga de tres vacas.ha- ${ }^{-1}$ tuvieron un periodo de descanso de veintiocho días y siete días de ocupación durante la duración del experimento. 


\section{Animales experimentales}

Se utilizaron dieciocho vacas gyr x pardo suizo de segundo parto, distribuidas en dos grupos experimentales de nueve animales. Cada grupo estaba constituido por tres vacas, el primero comprendido del día 1 hasta los $35 \pm 2$ días, el segundo hasta los 138 \pm 3 días y, en el último tercio hasta los 193 \pm 3 días de lactancia. Se asignó al azar una vaca de cada tercio de lactancia en cada uno de los cultivares de gramínea.

El ordeño de las vacas se realizó con el apoyo de ternero. Se ordeñaron tres cuartos de la ubre y se dejó disponible un cuarto para el consumo de leche por la cría durante 30 min. Para cuantificar la producción total de leche por vaca (vendible + consumida por la cría), se estimó la leche consumida por los terneros mediante la diferencia de peso antes del ordeño y 30 min después de haber mamado. Posteriormente, los terneros se trasladaron a un potrero de pasto Colosuana (Bothriochloa pertusa).

\section{Variables medidas}

\section{En las pasturas}

Se evaluó el forraje en oferta y la composición botánica en cada periodo experimental, antes de entrar las vacas a la parcela (Toledo y Schultze-Kraft, 1982). Se tomaron muestras de forraje simulando el pastoreo (pluck) de los animales y se secaron en horno durante $48 \mathrm{~h}$ a una temperatura de $55^{\circ} \mathrm{C}$ para su posterior análisis químico. Se realizó el análisis de proteína cruda (PC) (AOAC, 2010), fibra detergente neutro (FDN) y fibra en detergente ácido (FDA) (Van-Soest et al., 1991), grasa total por extracción con éter (EE) (AOAC, 2010), degradabilidad in situ de la materia seca (DISMS) (Ørskov et al., 1980) y perfil de ácidos grasos por cromatografía de gases.

La concentración de ácidos grasos en el forraje cosechado (hojas), se estimó a partir del extracto etéreo y con base en la ecuación de Allen (2000). La concentración de AG y el perfil lipídico (porcentaje AG del total de AG) se expresó en g.kg-1 materia seca (MS).

La extracción y metilación de los ácidos grasos en los forrajes, se realizó mediante modificación de las técnicas descritas por Garcés y Mancha (1993) y por Yamasaki et al. (1999). Al forraje (50 mg) se le adicionaron $2150 \mu l$ de metanol absoluto, $990 \mu \mathrm{l}$ de tolueno, $66 \mu \mathrm{l}$ de ácido sulfúrico al 99,9\%, $1000 \mu \mathrm{l}$ de N, N dimetilformamida y $2 \mathrm{ml}$ de n-hexano; la mezcla se colocó en un baño de María $\left(2 \mathrm{~h} \mathrm{a} 80^{\circ} \mathrm{C}\right)$, se dejó en reposo (5 - 10 min), se agitó y se recuperó el sobrenadante. El hexano del sobrenadante se evaporó mediante una corriente de nitrógeno. Al residuo se le adicionaron $300 \mu \mathrm{l}$ de diclorometano y se llevó a un vial con inserto cónico. Los ésteres de ácidos grasos metilados (FAMES) de la grasa de la leche y del forraje se cuantificaron por cromatografía de gases. Se utilizó un cromatógrafo de gases con auto inyector AOC20i y auto muestreador AOC20C. Los FAMES se separaron en columna capilar (Rt 2560; $100 \mathrm{~m}$ x 0,25 mm di x $0,2 \mu \mathrm{m}$ espesor de la capa). Las temperaturas del inyector y del detector de ionización de llama (FID) fueron $260{ }^{\circ} \mathrm{C}$ y $270{ }^{\circ} \mathrm{C}$, respectivamente. El programa de temperatura fue: $140{ }^{\circ} \mathrm{C}$ por $5 \mathrm{~min}$, se incrementó a $4{ }^{\circ} \mathrm{C} \cdot \mathrm{min}^{-1}$ hasta $190{ }^{\circ} \mathrm{C}$ y se mantuvo por $32,5 \mathrm{~min}$. El split ratio fue de 1 : 100 y el helio fue el gas de arrastre con una presión de 40,4 psi. Los tiempos de retención fueron comparados con estándares conocidos (Food Industry FAMEX Mix cat 35007).

\section{En los animales}

Durante el periodo de medición hubo un registro diario de la producción individual de leche vendible (tres cuartos mamarios) y se corrigió por grasa al $4 \%$ ( $\mathrm{kg}$ leche x 0,4 $+\mathrm{kg}$ grasa x 15). Se tomó una muestra de leche del ordeño total realizado a cada vaca en forma manual, para medir el contenido de proteína, grasa, lactosa, minerales y sólidos totales, con la utilización de un equipo autoanalizador de leche (Lactoscan) previamente calibrado. Además, 
se realizó la extracción del suero de la leche con renina comercial para su posterior análisis de nitrógeno ureico en leche (NUL) (Fawcett y Scott, 1960).

Para el análisis de ácidos grasos, la extracción de la grasa en la leche se realizó a través de modificaciones a las técnicas de separación mecánica descritas por Hurley et al. (1987) y Díaz et al. (2002). Se centrifugaron 100 $\mathrm{ml}$ de leche (15 min a $3000 \mathrm{rpm}$ ) y se retiró la fracción acuosa; el sobrenadante cremoso se mezcló con $15 \mathrm{ml}$ de solución detergente (50 g de hexametafosfato de sodio y $24 \mathrm{ml}$ de Tritón X100 disueltos en 11 de agua), se agitó, se colocó en baño de María $\left(10 \min\right.$ a $\left.90^{\circ} \mathrm{C}\right)$, y de nuevo se agitó y se puso en baño de María $\left(10\right.$ min a $\left.90{ }^{\circ} \mathrm{C}\right)$. La grasa de la capa superficial se retiró con una micropipeta y se almacenó a $-20{ }^{\circ} \mathrm{C}$. Se recolectaron $100 \mu \mathrm{l}$ de grasa y se solubilizaron en $900 \mu \mathrm{l}$ de diclorometano. Una alícuota de $20 \mu \mathrm{l}$ de esa mezcla, $20 \mu \mathrm{l}$ del reactivo de metil esterificación (0,2 M m-trifluorometilfenil-trimetilamonio hidróxido en metanol) y $160 \mu \mathrm{l}$ de diclorometano, se adicionaron en un vial con inserto cónico.

\section{Cálculos}

Los ácidos grasos de síntesis de novo, se cuantificaron mediante la suma de ácidos grasos menores a dieciséis carbonos. Los ácidos grasos preformados se cuantificaron mediante la sumatoria de los ácidos grasos de más de dieciséis carbonos (Rico, 2013).

El índice de actividad delta 9 desaturasa, que indica la producción de ácidos insaturados (C14:1, C16:1, C18:1 y ALC c9 t11) a partir de sustratos (C14:0, C16:0, C18:0 y C18:1 t11), se calculó con la ecuación de Gagliostro et al. (2006).

El índice de aterogenicidad, que indica la probabilidad de presentación de ateroesclerosis, se calculó con base en la concentración de ácidos grasos de 12, 14 y 16 carbonos, y la concentración de ácidos grasos insaturados (Ulbricht y Southgate, 1991).

El índice de trombogenicidad, que indica la probabilidad de presentación de trombosis coronaria en humanos, se calculó con base en la concentración de ácidos grasos saturados de 14, 16 y 18 carbonos, y la concentración de ácidos grasos monoinsaturados y poliinsaturados (omega 3 y 6) (Ulbricht y Southgate, 1991).

\section{Diseño experimental y análisis estadístico}

Se utilizó un diseño de cuadrado latino 3 x 3 replicado, al que se asignaron vacas en tres estados de lactancia (Amezquita, 1999). Para las variables medidas en las pasturas, se realizó un análisis de varianza con el empleo del modelo $Y_{\mathrm{ijk}}=\mu+\alpha_{\mathrm{i}}+\varrho_{\mathrm{j}}+\beta_{\mathrm{k}}+(\varrho \beta)_{\mathrm{jk}}+\varepsilon_{\mathrm{ijk}}$, donde $\mathrm{Y}_{\mathrm{ijk}}$ es la variable de interés, $\mu$ es el promedio general, $\alpha_{\mathrm{i}}$ es el efecto del cuadrado latino ( $i=1,2), \varrho_{j}$ es el efecto del periodo experimental $(j=1$ a 3$), \beta_{k}$ es el efecto de la especie (tratamiento) $(\mathrm{k}=1$ a 3$),(\varrho \beta)_{\mathrm{jk}}$ es el efecto de la interacción periodo x especie $(\mathrm{jk}=1$ a 9$)$ y $\varepsilon_{\mathrm{ijk}}$ es el error residual.

En las variables medidas en los animales se realizó un análisis de varianza con el empleo del modelo $\mathrm{Y}_{\mathrm{ijk} \mathrm{l}}=$ $\mu+\alpha_{\mathrm{i}}+\varrho_{\mathrm{j}}+\beta_{\mathrm{k}}+\theta_{1}+(\beta \theta)_{\mathrm{kl}}+\varepsilon_{\mathrm{ijkl}}$, donde $\mathrm{Y}_{\mathrm{ijkl}}$ es la variable de interés, $\mu$ es el promedio general, $\alpha_{\mathrm{i}}$ es el efecto del cuadrado latino $(i=1,2), \varrho_{j}$ es el efecto del periodo experimental $(j=1$ a 3$), \beta_{k}$ es el efecto de la especie $(k=1$ a $3), \theta_{1}$ es el efecto del tercio de lactancia $(1=1$ a 3$),(\beta \theta)_{\mathrm{kl}}$ es el efecto de la interacción especie $\mathrm{x}$ tercio de lactancia $\left(\mathrm{kl}=1\right.$ a 9) y $\varepsilon_{\mathrm{ijkl}}$ es el error residual. Para el análisis se utilizó el PROC MIXED del software SAS (2011) versión 9.3, y la comparación de medias se realizó con la prueba de Tukey con un nivel de significancia del $5 \%$.

\section{Nota comité de bioética}

La investigación contó con la aprobación del comité de bioética de la Facultad de Medicina Veterinaria y de Zootecnia de la Universidad Nacional de Colombia sede Bogotá (Acta 08, 6 de setiembre del 2012), en lo 
relacionado con el cumplimiento de las normas nacionales e internacionales de protección de los derechos de los animales y el uso y cuidado de animales para la experimentación.

\section{Resultados}

\section{Disponibilidad y composición botánica del forraje en oferta}

No se presentó interacción entre el tratamiento x periodo $(p>0,05)$. De acuerdo con lo planificado, la oferta de materia seca verde (MSV) (hojas y tallos) y hojas expresadas en kg.animal-1 $100 \mathrm{~kg}^{-1}$ de peso vivo (PV).día ${ }^{-1}$, fueron similares ( $\mathrm{p}>0,05)$ para los tres cultivares de gramíneas (23,2 a 26,7 $\mathrm{kg} \mathrm{MSV}^{-1} \cdot$ vaca.d ${ }^{-1}$ ) (Cuadro 2). La composición botánica de las pasturas fue dominada por las gramíneas sembradas ya que la contribución de otras especies fue baja y similar en los tres tratamientos (Cuadro 2).

Cuadro 2. Oferta de materia seca (MS), materia seca verde (MSV) y composición botánica en pasturas con tres cultivares de gramíneas tropicales, San Diego, Departamento del Cesar, Colombia, Mayo-Junio. 2013.

Table 2. Offer of dry matter (DM), green dry matter (MSV) and botanical composition in pastures with three cultivars of tropical grasses in San Diego, Cesar Department, Colombia, May-June. 2013.

\begin{tabular}{|c|c|c|c|c|c|}
\hline \multirow[t]{2}{*}{ Variable } & \multicolumn{3}{|c|}{ Cultivares de gramíneas } & \multirow[t]{2}{*}{ ESM } & \multirow[t]{2}{*}{$P$} \\
\hline & $\begin{array}{c}\text { Mulato II } \\
\text { (Brachiaria hibrido) }\end{array}$ & $\begin{array}{c}\text { Tanzania } \\
\text { (Megathyrsus maximus) }\end{array}$ & $\begin{array}{c}\text { Toledo } \\
\text { (Brachiaria brizantha) }\end{array}$ & & \\
\hline kg MS hojas ${ }^{-1}$.vaca.d d $^{-1}$ & 17,9 & 16,8 & 17,7 & 3,1 & 0,79 \\
\hline kg MS hojas ${ }^{-1} .100$ kg PV.d ${ }^{-1}$ & 4,3 & 4,4 & 4,4 & 0,8 & 0,93 \\
\hline kg MSV.vaca ${ }^{-1} \cdot d^{-1}$ & 26,7 & 23,6 & 23,2 & 4,3 & 0,46 \\
\hline kg MSV.100 kg-1 $\cdot$ PV.d ${ }^{-1}$ & 6,4 & 6,2 & 5,8 & 1,1 & 0,69 \\
\hline Relación hoja: tallo & 2,5 & 1,9 & 2,6 & 0,8 & 0,25 \\
\hline \multicolumn{6}{|l|}{ Composición botánica } \\
\hline Gramínea (\%) & 87,2 & 86,0 & 86,9 & 2,7 & 0,71 \\
\hline Colosuana $(\%)$ & 8,5 & 7,4 & 8,0 & 2,3 & 0,77 \\
\hline Leguminosas $(\%)$ & 1,5 & 1,9 & 1,8 & 1,5 & 0,86 \\
\hline Malezas (\%) & 2,8 & 4,7 & 3,3 & 1,0 & 0,08 \\
\hline
\end{tabular}

$\mathrm{ESM}=$ error estándar de la media de los tratamientos / ESM= Treatments standard error of the mean.

\section{Calidad nutricional de las gramíneas}

No hubo interacción entre el tratamiento y el periodo experimental $(p>0,05)$ en las variables evaluadas. El contenido de proteína cruda (PC) y EE de las hojas fue similar $(p>0,05)$ entre cultivares de gramíneas. Sin embargo, el pasto Tanzania presentó los mayores $(\mathrm{p}<0,05)$ contenidos de fibras (FDN y FDA) y la menor $(\mathrm{p}<0,05)$ degradabilidad de la materia seca (DISMS) (Cuadro 3).

\section{Perfil de ácidos grasos en gramíneas}

No se presentó interacción entre el tratamiento y el periodo experimental $(p>0,05)$ en las variables evaluadas. El contenido de ácidos grasos totales $\left(\mathrm{g} \mathrm{kg} \cdot \mathrm{MS}^{-1}\right)$ y la mayoría de $\mathrm{AG}$ individuales fueron similares $(\mathrm{p}>0,05)$ en los 
Cuadro 3. Calidad nutricional de tres cultivares de gramíneas tropicales evaluados bajo pastoreo en San Diego, Departamento del Cesar, Colombia, Mayo-Junio. 2013.

Table 3. Nutritional quality of three cultivars of tropical grasses evaluated under grazing in San Diego, Cesar Department, Colombia, May-June. 2013.

\begin{tabular}{lccccc}
\hline & \multicolumn{4}{c}{ Cultivares de gramíneas } & \\
\cline { 2 - 5 } Variable & $\begin{array}{c}\text { Mulato II } \\
\text { (Brachiaria hibrido) }\end{array}$ & $\begin{array}{c}\text { Tanzania } \\
\text { (Megathyrsus maximus) }\end{array}$ & $\begin{array}{c}\text { Toledo } \\
\text { (Brachiaria brizantha) }\end{array}$ & ESM & $\boldsymbol{P}$ \\
\hline PC (\%) & 7,3 & 8,9 & 6,7 & 1,3 & 0,09 \\
FDN (\%) & $66,1^{\mathrm{b}}$ & $69,6^{\mathrm{a}}$ & $66,8^{\mathrm{b}}$ & 0,9 & 0,005 \\
FDA (\%) & $35,7^{\mathrm{b}}$ & $40,2^{\mathrm{a}}$ & $36,7^{\mathrm{b}}$ & 0,9 & 0,01 \\
EE (\%) & $1,7^{\mathrm{b}}$ & 2,3 & 1,8 & 0,5 & 0,11 \\
DISMS (\%) & $62,1^{\mathrm{a}}$ & $56,8^{\mathrm{b}}$ & $59,8^{\mathrm{ab}}$ & 1,8 & 0,02 \\
\hline
\end{tabular}

ESM: error estándar de la media de los tratamientos. Letras diferentes en la misma fila indican diferencias significativas (p<0,05) según prueba de Tukey. PC: proteína cruda. FDN: fibra en detergente neutro. FDA: fibra en detergente ácido. DISMS: degradabilidad in situ de la materia seca. Letras diferentes en la misma fila indican diferencias estadísticas significativas $(\mathrm{p}<0,05)$ según prueba de tukey / ESM: treatments standard error of the mean. Different letters in the same row indicate significant differences $(\mathrm{p}<0.05)$ according to Tukey's test. PC: crude protein. FDN: neutral detergent fiber. FDA: acid detergent fiber. DISMS: dry matter in situ degradability. Different letters in the same row indicate significant differences $(\mathrm{P}<0.05)$ according to Tukey's test.

tres cultivares de gramíneas (Cuadro 3). Sin embargo, el contenido de ácido linolénico (C18:3 c9 c12 c15) tendió $(\mathrm{p}<0,10)$ a ser mayor en los pastos Tanzania y Toledo en comparación con Mulato II, y la relación ácido linoleico/ linolénico fue numéricamente mayor en el pasto Mulato II (Cuadro 4).

Cuadro 4. Contenido de ácidos grasos totales y perfil de ácidos grasos en tres cultivares de gramíneas tropicales en San Diego, Departamento del Cesar, Colombia. Mayo-junio, 2013.

Table 4. Total fatty acids content and fatty acid profile in three cultivars of tropical grasses in San Diego, Cesar Department, Colombia. May-June, 2013.

\begin{tabular}{|c|c|c|c|c|c|}
\hline \multirow[b]{3}{*}{ Ácidos grasos } & \multicolumn{3}{|c|}{ Cultivares de gramíneas } & \multirow[b]{3}{*}{ ESM } & \multirow[b]{3}{*}{$P$} \\
\hline & $\begin{array}{c}\text { Mulato II } \\
\text { (Brachiaria hibrido) } \\
\end{array}$ & $\begin{array}{c}\text { Tanzania } \\
\text { (Megathyrsus maximus) }\end{array}$ & $\begin{array}{c}\text { Toledo } \\
\text { (Brachiaria brizantha) } \\
\end{array}$ & & \\
\hline & \multicolumn{3}{|c|}{$\mathrm{g} / \mathrm{kg} \mathrm{MS}$} & & \\
\hline AG totales & 7,7 & 14,3 & 8,5 & 5,4 & 0,11 \\
\hline C14:0 & 0,36 & 1,03 & 0,36 & 0,65 & 0,14 \\
\hline C16:0 & 3,06 & 5,80 & 2,90 & 2,00 & 0,13 \\
\hline $\mathrm{C} 18: 0$ & 0,18 & 0,45 & 0,32 & 0,35 & 0,28 \\
\hline C18:1 c9 & 0,77 & 1,61 & 0,87 & 0,73 & 0,13 \\
\hline $\mathrm{C} 18: 2 \mathrm{c} 9 \mathrm{c} 12$ & 0,73 & 0,80 & 0,99 & 0,39 & 0,63 \\
\hline $\mathrm{C} 18: 3 \mathrm{c} 9 \mathrm{c} 12 \mathrm{c} 15$ & 0,54 & 1,20 & 1,08 & 0,47 & 0,09 \\
\hline Precursores ALC & 1,28 & 2,00 & 2,08 & 0,69 & 0,19 \\
\hline $\mathrm{C} 18: 2 / \mathrm{C} 18: 3$ & 1,34 & 0,66 & 0,91 & 0,46 & 0,29 \\
\hline
\end{tabular}

ESM: error estándar de la media de los tratamientos / ESM: treatments standard error of the mean. 


\section{Producción y composición de la leche}

No hubo interacción del tratamiento y el tercio de lactancia $(\mathrm{p}>0,05)$ en las variables evaluadas. La producción de leche vendible, total por vaca (vendible + consumida por el ternero) y corregida por grasa al $4 \%$ fue similar $(\mathrm{p}>0,05)$ en los tres cultivares de gramíneas (Cuadro 4). Como era de esperarse, la producción diaria de leche (vendible, total y corregida por grasa al $4 \%$ ) disminuyó a medida que aumentó el tercio de lactancia (Cuadro 5).

Cuadro 5. Producción de leche de vacas en pastoreo gyr x pardo suizo de segundo parto en función de tres cultivares de gramíneas tropicales y tercios de lactancia en San Diego, Departamento del Cesar, Colombia. Mayo-Junio, 2013.

Table 5. Milk production of grazing Gyr x Brown Swiss cows second birth in function of three tropical grasses cultivars and third of lactation in San Diego, Cesar Department, Colombia. May-June, 2013.

\begin{tabular}{|c|c|c|c|c|c|}
\hline \multirow[b]{2}{*}{ Variable } & \multicolumn{3}{|c|}{ Cultivares de gramíneas } & \multirow[b]{2}{*}{ ESM } & \multirow[b]{2}{*}{$P$} \\
\hline & $\begin{array}{c}\text { Mulato II } \\
\text { (Brachiaria hibrido) }\end{array}$ & $\begin{array}{c}\text { Tanzania } \\
\text { (Megathyrsus maximus) }\end{array}$ & $\begin{array}{c}\text { Toledo } \\
\text { (Brachiaria brizantha) }\end{array}$ & & \\
\hline Vendible $\left(\mathrm{kg}^{-1} \cdot\right.$.vaca $\left.\cdot \mathrm{d}^{-1}\right)$ & 4,7 & 4,8 & 4,8 & 0,75 & 0,93 \\
\hline Total $\left(\mathrm{kg}^{-1} \cdot\right.$ vaca.d $\left.\mathrm{d}^{-1}\right)$ & 6,6 & 6,3 & 6,6 & 0,87 & 0,50 \\
\hline \multirow[t]{2}{*}{ Total LCG $4 \%\left(\mathrm{~kg}^{-1}\right.$.vaca. $\left.\mathrm{d}^{-1}\right)$} & 6,7 & 6,9 & 6,8 & 1,16 & 0,84 \\
\hline & & Tercio de lactancia & & & \\
\hline Variable & Primer & Segundo & Tercero & ESM & $P$ \\
\hline Vendible $\left(\mathrm{kg}^{-1} \cdot\right.$ vaca $\left.\cdot \mathrm{d}^{-1}\right)$ & $5,9^{\mathrm{a}}$ & $4,5^{\mathrm{b}}$ & $3,9^{b}$ & 0,16 & 0,0001 \\
\hline Total $\left(\mathrm{kg}^{-1} \cdot\right.$ vaca. $\left.\mathrm{d}^{-1}\right)$ & $8,2^{\mathrm{a}}$ & $6,0^{\mathrm{b}}$ & $5,2^{\mathrm{c}}$ & 0,22 & 0,0001 \\
\hline Total LCG $4 \%\left(\mathrm{~kg}^{-1}\right.$.vaca $\left.\cdot \mathrm{d}^{-1}\right)$ & $8,4^{\mathrm{a}}$ & $6,4^{\mathrm{b}}$ & $5,6^{\mathrm{b}}$ & 0,22 & 0,0001 \\
\hline
\end{tabular}

ESM: error estándar de la media. LCG (Leche corregida por grasa $4 \%)=(0,4$ x PLT) +15 x kg G. PLT: producción de leche total. G: grasa $\mathrm{kg} . \mathrm{d}^{-1}$. Letras diferentes en la misma fila indican diferencias significativas $(\mathrm{P}<0,05)$ según prueba de Tukey / ESM: Treatments standard error of the mean. LCG (Milk corrected by $4 \%$ fat $)=(0.4 \mathrm{x}$ PLT $)+15 \mathrm{x} \mathrm{kg} \mathrm{G}$. PLT: total milk production. G: fat kg.d ${ }^{-1}$. Different letters in the same row indicate significant differences $(\mathrm{P}<0.05)$ according to Tukey's test.

Las concentraciones de sólidos totales, lactosa, minerales y nitrógeno ureico (NUL) en la leche vendible de las vacas fueron similares $(p>0,05)$ en los diferentes cultivares de gramíneas (Cuadro 6). Sin embargo, la concentración de proteína y de grasa fue mayor $(\mathrm{p}<0,05)$ en la leche de vacas que consumieron el pasto Mulato II y Tanzania, respectivamente (Cuadro 5). El tercio de lactancia no afectó $(\mathrm{p}>0,05)$ la concentración de sólidos totales, proteína, grasa, lactosa y minerales en la leche vendible de las vacas (Cuadro 6).

\section{Perfil de ácidos grasos en la grasa de la leche}

No hubo interacción entre el tratamiento y el tercio de lactancia sobre el perfil de AG en la leche en las variables evaluadas. El pasto Tanzania presentó la menor $(\mathrm{p}<0,05)$ concentración en la sumatoria de los ácidos grasos $\mathrm{C} 12, \mathrm{C} 14$ y C16. En contraste, las vacas alimentadas con este cultivar presentaron las mayores $(\mathrm{p}<0,05)$ concentraciones de ácido esteárico (C18:0), ácido transvaccénico (C18:1 t11) y ALC (c9 t11) en la grasa de la leche (Cuadro 7), a pesar de la menor relación linoleico/linolénico contenido en este forraje y a las concentraciones similares de precursores de ALC que presentaron los tres cultivares (Cuadro 4). 
Cuadro 6. Calidad composicional de la leche vendible de vacas gyr x pardo suizo de segundo parto en función de tres cultivares de gramíneas tropicales y de tercios de lactancia en San Diego, Departamento del Cesar, Colombia. Mayo-Junio. 2013.

Table 6. Compositional quality of saleable milk of second birth gyr x Brown Swiss cows in function of three tropical grasses cultivars and thirds of lactation in San Diego, Cesar Department, Colombia. May-June. 2013.

\begin{tabular}{|c|c|c|c|c|c|}
\hline \multirow[b]{2}{*}{ Componente } & \multicolumn{3}{|c|}{ Cultivares de gramíneas } & \multirow[b]{2}{*}{ ESM } & \multirow[b]{2}{*}{$P$} \\
\hline & $\begin{array}{c}\text { Mulato II } \\
\text { (Brachiaria hibrido) }\end{array}$ & $\begin{array}{c}\text { Tanzania } \\
\text { (Megathyrsus maximus) }\end{array}$ & $\begin{array}{c}\text { Toledo } \\
\text { (Brachiaria brizantha) }\end{array}$ & & \\
\hline Sólidos totales (\%) & 13,00 & 13,30 & 12,90 & 0,69 & 0,16 \\
\hline Proteína (\%) & $3,33^{\mathrm{a}}$ & $3,26^{\mathrm{b}}$ & $3,28^{\mathrm{ab}}$ & 0,09 & 0,04 \\
\hline Grasa $(\%)$ & $4,17^{\mathrm{b}}$ & $4,70^{\mathrm{a}}$ & $4,23^{\mathrm{b}}$ & 0,66 & 0,04 \\
\hline Lactosa $(\%)$ & 4,66 & 4,57 & 4,59 & 0,11 & 0,06 \\
\hline Minerales (\%) & 0,77 & 0,76 & 0,76 & 0,02 & 0,17 \\
\hline \multirow[t]{2}{*}{ NUL (mg/dl) } & 12,00 & 14,80 & 13,40 & 5,61 & 0,35 \\
\hline & & Tercio de lactancia & & & \\
\hline Componente & Primero & Segundo & Tercero & ESM & $P$ \\
\hline Sólidos totales (\%) & 12,80 & 13,10 & 13,30 & 0,09 & 0,11 \\
\hline Proteína (\%) & 3,29 & 3,28 & 3,31 & 0,01 & 0,63 \\
\hline Grasa $(\%)$ & 4,12 & 4,46 & 4,53 & 0,09 & 0,15 \\
\hline Lactosa $(\%)$ & 4,60 & 4,58 & 4,65 & 0,01 & 0,24 \\
\hline Minerales (\%) & 0,77 & 0,76 & 0,76 & 0,002 & 0,35 \\
\hline NUL (mg/dl) & 13,40 & 14,20 & 12,70 & 0,81 & 0,74 \\
\hline
\end{tabular}

ESM: error estándar de la media. NUL: nitrógeno ureico en leche. Letras diferentes en la misma fila indican diferencias significativas $(\mathrm{p}<0,05)$ según prueba de Tukey / ESM: treatments standard error of the mean. NUL: milk ureic nitrogen. Different letters in the same row indicate significant differences $(\mathrm{p}<0.05)$ according to Tukey's test.

La concentración de ácidos grasos de síntesis de novo en la grasa de la leche fue similar $(\mathrm{p}>0,05)$ en las vacas alimentadas con los tres cultivares, pero con el pasto Tanzania se presentó una mayor $(p<0,05)$ concentración de ácidos grasos preformados en la grasa de la leche. La concentración de ácidos grasos poliinsaturados en la grasa de la leche fue mayor $(\mathrm{p}<0,05)$ en las vacas alimentadas con el pasto Tanzania y Toledo en comparación con Mulato II (Cuadro 6). Los índices de la delta 9 desaturasa, de sus productos/sustratos y los índices de aterogenicidad y trombogenicidad en la grasa de la leche de las vacas no se afectaron $(\mathrm{p}<0,05)$ por los diferentes cultivares (Cuadro 7).

En este estudio se presentaron diferencias en la concentración de AG en la grasa de la leche, debido a los tercios de lactancia. En forma general, se observó que conforme progresó la lactancia hubo una tendencia a incrementar la concentración de ácido margárico (C17:0) y a disminuir las concentraciones de los ácidos grasos linoleico (C18:2) y linolénico (C18:3) en la grasa de la leche de las vacas (Cuadro 8). Las concentraciones de los ácidos palmitoleico (C16:1), oleico (C18:1), insaturados, monoinsaturados y poliinsaturados fueron mayores $(\mathrm{p}<0,05)$ en la grasa de la leche de las vacas de segundo tercio en comparación con las de primer y último tercio de lactancia. La concentración de los AG esteárico $(\mathrm{C} 18: 0)$ y saturados fueron mayores $(\mathrm{p}<0,05)$ en la grasa de la leche de las vacas de primer y último tercio de lactancia. La sumatoria de la concentración de los AG C12, C14 y C16 en la grasa de la leche de las vacas fue similar $(p>0,05)$ entre los diferentes cultivares (Cuadro 8). 
Cuadro 7. Perfil de ácidos grasos en la grasa de la leche vendible de vacas Gyr x Pardo Suizo de segundo parto alimentadas con tres cultivares de gramíneas tropicales en San Diego, Departamento del Cesar, Colombia, Mayo-Junio. 2013.

Table 7. Fatty acid profile in the saleable milk fat of second birth Gyr x Brown Swiss cows fed with cultivars of tropical grasses in San Diego,Cesar Department, Colombia, May-June. 2013.

\begin{tabular}{|c|c|c|c|c|c|}
\hline \multirow[b]{3}{*}{ Ácidos grasos } & \multicolumn{3}{|c|}{ Cultivares de gramíneas } & \multirow[b]{3}{*}{ ESM } & \multirow[b]{3}{*}{$P$} \\
\hline & $\begin{array}{c}\text { Mulato II } \\
\text { (Brachiaria hibrido) }\end{array}$ & $\begin{array}{c}\text { Tanzania } \\
\text { (Megathyrsus maximus) }\end{array}$ & $\begin{array}{c}\text { Toledo } \\
\text { (Brachiaria brizantha }) \\
\end{array}$ & & \\
\hline & \multicolumn{3}{|c|}{$\mathrm{mg} \mathrm{g}^{-1} \mathrm{AG}$} & & \\
\hline $\mathrm{C} 12: 0+\mathrm{C} 14: 0+\mathrm{C} 16: 0$ & $478,0^{\mathrm{a}}$ & $439,3^{b}$ & $448,5^{\mathrm{ab}}$ & 15,94 & 0,03 \\
\hline C16:1 c9 & 17,7 & 16,8 & 16,2 & 4,42 & 0,58 \\
\hline $\mathrm{C} 17: 0$ & 4,0 & 4,2 & 3,6 & 0,84 & 0,10 \\
\hline $\mathrm{C} 18: 0$ & $83,3^{\mathrm{b}}$ & $98,1^{\mathrm{a}}$ & $93,4^{\mathrm{ab}}$ & 16,1 & 0,02 \\
\hline C18:1 c9 & 209,9 & 224,7 & 224,8 & 40,4 & 0,44 \\
\hline C18:1 t11(ATV) & $19,8^{\mathrm{b}}$ & $24,4^{\mathrm{a}}$ & $24,2^{\mathrm{a}}$ & 4,65 & 0,007 \\
\hline $\mathrm{C} 18: 2 \mathrm{c} 9 \mathrm{c} 12(\mathrm{AL})$ & 5,8 & 6,6 & 6,6 & 1,34 & 0,11 \\
\hline C18:2 c9 t11 (ALC) & $12,3^{\mathrm{b}}$ & $14,6^{\mathrm{a}}$ & $14,0^{\mathrm{ab}}$ & 2,86 & 0,05 \\
\hline C18:3 c9 c12 c15 (ALN) & $4,1^{\mathrm{b}}$ & $5,2^{\mathrm{a}}$ & $4,8^{\mathrm{ab}}$ & 1,21 & 0,02 \\
\hline AL/ALN & 1,6 & 1,3 & 1,4 & 0,43 & 0,17 \\
\hline AG, según saturación & \multicolumn{5}{|c|}{$\mathrm{mg} \mathrm{g}^{-1} \mathrm{AG}$} \\
\hline Saturados & 663,0 & 638,3 & 640,1 & 53,0 & 0,30 \\
\hline Insaturados & 318,5 & 342,4 & 340,2 & 51,0 & 0,31 \\
\hline Monoinsaturados & 293,8 & 313,0 & 311,0 & 45,9 & 0,39 \\
\hline Poliinsaturados & $24,7^{\mathrm{b}}$ & $29,4^{\mathrm{a}}$ & $29,2^{\mathrm{a}}$ & 6,1 & 0,04 \\
\hline AG, según origen & \multicolumn{5}{|c|}{$\mathrm{mg} \mathrm{g}^{-1} \mathbf{A G}$} \\
\hline De novo $(<16 \mathrm{C})$ & 262,8 & 257,0 & 254,2 & 22,9 & 0,47 \\
\hline Preformados (> 16 C) & $380,6^{\mathrm{b}}$ & $420,8^{\mathrm{a}}$ & $413,9^{\mathrm{ab}}$ & 38,4 & 0,04 \\
\hline Índice delta 9 desaturasa & 0,30 & 0,33 & 0,33 & 0,05 & 0,43 \\
\hline C14:1/C14:0 & 0,04 & 0,05 & 0,05 & 0,007 & 0,87 \\
\hline C16:1/C16:0 & 0,05 & 0,06 & 0,05 & 0,006 & 0,83 \\
\hline C18:1/C18:0 & 2,6 & 2,5 & 2,6 & 0,27 & 0,90 \\
\hline CLA/ATV & 0,7 & 0,6 & 0,6 & 0,004 & 0,12 \\
\hline Indice aterogenicidad & 2,6 & 2,3 & 2,4 & 0,14 & 0,18 \\
\hline Indice trombogenicidad & 3,3 & 3,0 & 3,1 & 0,19 & 0,25 \\
\hline
\end{tabular}

ATV: ácido transvaccénico. AL: ácido linoleico. ALC: ácido linolénico conjugado. ALN: ácido linolénico. ESM: error estándar de la media de los tratamientos. Letras diferentes en la misma fila indican diferencias significativas $(\mathrm{p}<0,05)$ según prueba de Tukey / ATV: transvaccenic acid. AL: linoleic acid. ALC: conjugated linolenic acid. ALN: linolenic acid. ESM: treatments standard error of the mean. Different letters in the same row indicate significant differences $(\mathrm{p}<0.05)$ according to Tukey's test.

\section{Discusión}

Diversos estudios han sugerido que las variaciones en el perfil graso de la leche se pueden explicar por el perfil y aporte lipídico de la dieta (Schmidely et al., 2008; Shingfield et al., 2013). La mayor concentración de grasa en la leche de las vacas con el pasto Tanzania, podría estar relacionada por un posible consumo mayor de AG en comparación con el pasto Mulato II y Toledo. El cultivar Tanzania realizó un mayor aporte de AG (totales, saturados y de $\geq 18$ carbonos) en comparación con el pasto Mulato II y Toledo, lo cual pudo influir sobre el alto 
Cuadro 8. Perfil de ácidos grasos en la grasa de la leche vendible de vacas gyr x pardo suizo de segundo parto en diferentes tercios de lactancia en pastoreo de tres cultivares de gramíneas tropicales en San Diego, Departamento del Cesar, Colombia. Mayo-Junio, 2013.

Table 8. Fatty acid profile in saleable milk fat of second birth gyr x Brown Swiss cows, in different thirds of lactation in grazing of three cultivars tropical grasses in San Diego, Cesar Department, Colombia. May-June, 2013.

\begin{tabular}{|c|c|c|c|c|c|}
\hline \multirow[b]{2}{*}{ Ácidos grasos } & \multicolumn{3}{|c|}{ Tercio de lactancia } & \multirow[b]{2}{*}{ ESM } & \multirow[b]{2}{*}{$\boldsymbol{P}$} \\
\hline & Primer & $\begin{array}{c}\text { Segundo } \\
\mathrm{mg} \mathrm{g}^{-1} \mathrm{AG}\end{array}$ & Tercero & & \\
\hline $\mathrm{C} 12: 0+\mathrm{C} 14: 0+\mathrm{C} 16: 0$ & 460,6 & 436,2 & 470,9 & 11,97 & 0,09 \\
\hline C16:1 & $14,0^{\mathrm{b}}$ & $20,0^{\mathrm{a}}$ & $16,9^{\mathrm{ab}}$ & 6,9 & 0,001 \\
\hline $\mathrm{C} 17: 0$ & $3,9^{\mathrm{ab}}$ & $3,6^{\mathrm{b}}$ & $4,3^{\mathrm{a}}$ & 1,4 & 0,04 \\
\hline $\mathrm{C} 18: 0$ & $100,1^{\mathrm{a}}$ & $79,3^{\mathrm{b}}$ & $95,4^{\mathrm{a}}$ & 25,5 & 0,0009 \\
\hline C18:1 c9 & $209,5^{\mathrm{b}}$ & $243,8^{\mathrm{a}}$ & $206,0^{\mathrm{b}}$ & 58,1 & 0,001 \\
\hline C18:1 t11 (ATV) & 22,4 & 22,6 & 23,3 & 8,4 & 0,81 \\
\hline $\mathrm{C} 18: 2$ c9 c12 (AL) & $6,5^{\mathrm{a}}$ & $7,0^{\mathrm{a}}$ & $5,4^{\mathrm{b}}$ & 2,0 & 0,002 \\
\hline C18:2 c9 t11 (ALC) & 12,7 & 14,5 & 13,7 & 4,2 & 0,18 \\
\hline C18:3 c9 c12 c15 (ALN) & $5,1^{\mathrm{a}}$ & $5,2^{\mathrm{a}}$ & $3,7^{\mathrm{b}}$ & 2,2 & 0,001 \\
\hline Relación AL/ALN & 1,4 & 1,5 & 1,5 & 0,6 & 0,68 \\
\hline AG según saturación & & & $\mathrm{mg} \mathrm{g}^{-1} \mathrm{AG}$ & & \\
\hline Saturados & $662,7^{\mathrm{a}}$ & $613,6^{\mathrm{b}}$ & $665,0^{\mathrm{a}}$ & 79,9 & 0,008 \\
\hline Insaturados & $318,9^{\mathrm{b}}$ & $365,9^{\mathrm{a}}$ & $316,3^{\mathrm{b}}$ & 76,1 & 0,008 \\
\hline Monoinsaturados & $292,3^{\mathrm{b}}$ & $334,1^{\mathrm{a}}$ & $291,4^{\mathrm{b}}$ & 66,9 & 0,01 \\
\hline Poliinsaturados & $26,6^{\mathrm{b}}$ & $31,8^{\mathrm{a}}$ & $24,9^{\mathrm{b}}$ & 10,2 & 0,004 \\
\hline AG según origen & & & $\mathrm{mg} \mathrm{g}^{-1} \mathbf{A G}$ & & \\
\hline De novo $(<16 \mathrm{C})$ & 266,7 & 253,5 & 253,8 & 23,7 & 0,11 \\
\hline Preformados (> 16 C) & 398,4 & 424,5 & 392,4 & 43,6 & 0,12 \\
\hline Índice delta 9 desaturasa & $0,30^{\mathrm{b}}$ & $0,36^{\mathrm{a}}$ & $0,30^{\mathrm{b}}$ & 0,08 & 0,003 \\
\hline C14:1/C14:0 & 0,05 & 0,06 & 0,04 & 0,001 & 0,55 \\
\hline C16:1/C16:0 & $0,04^{\mathrm{b}}$ & $0,07^{\mathrm{a}}$ & $0,05^{\mathrm{b}}$ & 0,004 & 0,001 \\
\hline C18:1/C18:0 & $2,1^{\mathrm{b}}$ & $3,3^{\mathrm{a}}$ & $2,2^{\mathrm{b}}$ & 0,19 & 0,0002 \\
\hline CLA/ATV & 0,6 & 0,7 & 0,6 & 0,002 & 0,10 \\
\hline Indice aterogenicidad & $2,5^{\mathrm{ab}}$ & $2,1^{\mathrm{b}}$ & $2,6^{\mathrm{a}}$ & 0,10 & 0,02 \\
\hline Indice trombogenicidad & $3,2^{\mathrm{ab}}$ & $2,7^{\mathrm{b}}$ & $3,4^{\mathrm{a}}$ & 0,14 & 0,007 \\
\hline
\end{tabular}

ATV: ácido transvaccénico. AL: ácido linoleico. ALC: ácido linolénico conjugado. ALN: ácido linolénico. ESM: error estándar de la media. Letras entre las filas indican diferencias significativas $(\mathrm{p}<0,05)$ según prueba de Tukey / ATV: transvaccenic acid. AL: linoleic acid. ALC: conjugated linolenic acid. ALN: linolenic acid. ESM= treatments standard error of the mean. Letters between rows indicate significant differences $(\mathrm{p}<0.05)$ according to Tukey's test.

contenido de grasa en la leche de las vacas alimentadas con este cultivar. En un meta-análisis de la relación entre el flujo de AG al duodeno y la síntesis de grasa en la glándula mamaria, se observó que cuando la concentración de $A G \geq 18$ carbonos estaba por debajo de $51,7 \%$ en la grasa láctea, la adición de grasa a la ración aumentaba las concentraciones de estos AG en la leche (Glasser et al., 2008). Adicionalmente, Schroeder et al. (2004) indicaron que la suplementación con grasas, principalmente saturadas, incrementa la concentración de grasa en la leche.

El mayor contenido de precursores de ALC en la leche (linoleico + linolénico) presentes en el pasto Tanzania, concordó con lo observado por Mojica et al. (2017), quienes identificaron a este cultivar como promisorio para generar un contenido mayor de ALC (c9 t11) en la grasa de la leche en comparación con las otras especies evaluadas. 
Con la utilización de un suplemento rico en C16:0 (47 g.100 g-1 AG totales), se incrementó la concentración $(21,4 \%)$ y la producción diaria $(30,8 \%)$ de C16:0 en la grasa de la leche de vacas Holstein (Lock et al., 2013). Por lo tanto, en este estudio se esperaba una mayor concentración en la sumatoria de los ácidos grasos C12, C14 y C16 en la grasa de la leche las vacas al consumir el pasto Tanzania, debido a su mayor contenido de C16:0. Sin embargo, en la grasa de la leche de las vacas alimentadas con el cultivar Tanzania se observó una menor concentración de ácido palmítico (C16:0) (302,9 mg.g $\mathrm{g}^{-1}$ grasa), en comparación con las vacas alimentadas con pasto Toledo y Mulato II (312,1 y 338,0 mg/g grasa, respectivamente), lo que podría deberse a la mayor concentración de ácidos grasos poliinsaturados en la grasa de la leche de las vacas alimentadas con Tanzania (29,4 mg.g ${ }^{-1}$ grasa), los cuales se han identificado como inhibidores de la síntesis mamaria de ácidos grasos de novo (Harvatine et al., 2009).

El ácido esteárico (C18:0) en la grasa de la leche proviene de la biohidrogenación ruminal del ácido linoleico (C18:2) y linolénico (C18:3) (Chilliard y Ferlay, 2004), el aporte de microorganismos ruminales (Bas et al., 2003; Varádyová et al., 2008) y la dieta (Dohme et al., 2004). En este estudio el contenido de ácido esteárico (C18:0) en los tres cultivares evaluados fue bajo, lo cual coincide con lo reportado en otros estudios con forrajes (Boufaied et al., 2003; Khan et al. 2015), y sugiere una baja influencia de estas dietas sobre la concentración de este AG en la grasa de la leche. La mayor concentración de C18:0 en la grasa de la leche de las vacas alimentadas con los pastos Tanzania y Toledo, posiblemente pudo estar relacionado con un mayor aporte de C18:0 por los microorganismos ruminales, debido a que se ha identificado una alta concentración (alrededor de $50 \%$ ) de este AG en los microorganismos (Bas et al., 2003; Varádyová et al., 2008). Sin embargo, esta variable no fue analizada en este estudio.

El ácido linolénico (C18:3) es uno de los precursores de ácido transvaccénico (C18:1 t11) en el rumen, el cual a su vez es el sustrato para la síntesis endógena de ALC (c9 t11) en la glándula mamaria (Griinari et al., 2000; Mosley et al., 2006). Los cultivares Tanzania y Toledo aportaron un mayor contenido de ácido linolénico y generaron mayores concentraciones de los ácidos transvaccénico y ALC en la grasa de la leche de las vacas, como se observó en el estudio de Scerra et al. (2016), en el cual una alta concentración (19,7 mg.g ${ }^{-1}$ grasa) de ALC (c9 t11) en la grasa de la leche en vacas se originó a partir de una dieta con alta proporción de leguminosas que realizaron importantes aportes de ácido linolénico $(59,2 \%)$.

La producción de leche disminuyó, pero se observó una tendencia a incrementar la concentración de grasa en la leche conforme progresó la lactancia en las vacas, lo cual concuerda con el estudio de Mojica et al. (2013) en el que se evaluó la producción y composición de la leche en vacas doble propósito en el departamento del Cesar, Colombia.

En este estudio la concentración de los AG de síntesis de novo en la grasa de la leche no se incrementaron conforme progresó la lactancia de las vacas, en contraste con resultados de otros estudios en los que se ha reportado un incremento en la concentración esos AG y una reducción en la concentración de los AG preformados, a partir de la movilización de los tejidos corporales, a medida que la lactación progresa (Palmquist et al., 1993; Stoop et al., 2009; Bilal et al., 2014).

El aumento en la concentración de C18:0 en la grasa de la leche de las vacas en el primer y último tercio de lactancia, posiblemente se puede explicar por una mayor biohidrogenación ruminal de los ácidos linoleico (C18:2) y linolénico (C18:3). En contraste, en las vacas de segundo tercio de lactancia, posiblemente se presentó una menor biohidrogenación ruminal de C18:2 y C18:3, que produjo una menor concentración de C18:0 en la grasa de la leche. En vacas en el primer y último tercio de lactancia, la mayor concentración de C18:0 y de C17:0 en la grasa de la leche, posiblemente se explica por aportes de AG realizados por los microorganismos ruminales (Doreau y Chilliard, 1997; Varádyová et al., 2008).

Las concentraciones de C16: y C18:1 fueron mayores en la grasa de la leche de las vacas en segundo tercio de lactancia debido posiblemente a mayor actividad de la delta 9 desaturasa en sus respectivos productos/sustratos (C16:1/C16:0 y C18:1/C18:0), que regula la producción de AG insaturados en la glándula mamaria y tejido adiposo de rumiantes (Corl et al., 2001). Esta enzima actúa sobre diferentes sustratos (C14:0, C16:0, C18:0, C18:1 t11) para 
sintetizar C14:1, C16:1, C18:1, ALC c9 t11 en la glándula mamaria (Ntambi y Makoto, 2003). Estos resultados son contrarios al estudio de Kgwatalala et al. (2009) con vacas Yersey, pues en este caso los autores no observaron diferencia en la concentración de C16:1, pero sí una menor concentración de C18:1 en la grasa de la leche en vacas de segundo tercio de lactancia.

En este estudio la concentración de ALC (c9 t11) en la grasa de la leche no varió entre tercios de lactancia, lo cual sí se ha observado en estudios realizados en vacas de lechería especializadas con pastos de zonas templadas, donde se ha reportado una mayor concentración de ALC (c9 t11) en vacas de segundo y tercer tercio de lactancia, que en vacas de primer tercio (Kay et al., 2005; Kgwatalala et al., 2009; Stoop et al., 2009).

No hubo una tendencia definida en la concentración de ácidos grasos saturados y poliinsaturados por efecto del tercio de lactancia. Esto contrasta con resultados de Kay et al. (2005), quienes reportaron un incremento (51\%) en la concentración de ácidos provenientes de la síntesis de novo (4:0 a 14:0) y una disminución (15\%) en los ácidos grasos preformados $(\geq 17: 0)$ al aumentar los días de lactancia en vacas Holstein.

La leche producida con los tres cultivares evaluados en este estudio, presentaron mayores concentraciones de C8:0, C10:0, C12:0, C14:0, C16:0, concentrados similares de C18:3 y ALC (c9 t11) y menores cantidades de C18:0, C18:1, C18:2, en comparación con el perfil de ácidos grasos (promedio) en leche proveniente de sistemas especializados con forrajes de zonas templadas en Colombia (Rico et al., 2007; León, 2011; Gastón et al., 2014; Parales, 2015). Con base en lo anterior, los AG saturados en la leche obtenida con los tres cultivares, generarían un efecto negativo sobre la salud humana, sin embargo, debido a la alta concentración de ALC (c9 t11) en la leche se podría conferir un efecto positivo, debido a sus efectos nutraceúticos (anticarcinogénico, antiaterogénico) (Bhattacharya et al., 2006).

Si se tiene como base la concentración de ALC (c9 t11) promedio (13,6 mg.g $\mathrm{g}^{-1}$ grasa) en la grasa de la leche y el contenido de grasa en la leche $(3,54 \%)$ de vacas holstein en la Sabana de Bogotá, del estudio de Rico et al. (2007), la concentración de ALC (c9 t11) en la leche sería aproximadamente de 481,4 mg.1 $1^{-1}$, lo cual está por debajo de las concentraciones observadas en las leches de este estudio. Si se consideran los contenidos de ALC (c9 t11) de grasa en la leche, las vacas alimentadas con el pasto Tanzania y Toledo presentaron mayores concentraciones de $\operatorname{ALC}$ (686,2 y 592,2 mg. $1^{-1}$, respectivamente) en comparación con las vacas holstein del estudio de Rico et al. (2007). Con un consumo diario de leche percapita en Colombia de $397 \mathrm{ml}$ para el año 2017 (FEDEGAN, 2018), esa cantidad consumida de leche, producida con pasto Tanzania y Toledo, representaría una ingestión de 0,27 y 0,23 g.d $\mathrm{d}^{-1}$ de ALC, respectivamente. Con base en lo anterior, se realizaría un aporte de $81,8 \%$ y $69,7 \%$, para alcanzar un consumo de ALC en una persona de 0,33 g.d $\mathrm{d}^{-1}$, a partir de leche con una concentración de ALC de 15,8 mg.g ${ }^{-1}$ de grasa, necesario para disminuir en un $43 \%$ el riesgo de infarto de miocardio no fatal (Smit et al., 2015).

El mayor contenido de ácido oleico (C18:1) y de AG poliinsaturados en la grasa de la leche en las vacas alimentadas con los pastos Tanzania y Toledo, puede contribuir a generar efectos positivos sobre la salud humana, ya que se le ha atribuido reducciones de colesterol LDL, triglicéridos y aumentos en el colesterol HDL por el consumo de C18:1 en humanos (López, 2010; Haeiwa et al., 2014), además, se disminuye en el riesgo (10 \%) de presentación de enfermedades coronarias (Micha y Mozzafrian, 2010) por el consumo de dietas con mayores niveles de AG poliinsaturados (Bunout y Escobar, 2000, Mozaffarian et al., 2010) o el reemplazo de AG saturados por poliinsaturados (5\% de sustitución de energía). Sin embargo, Ortega et al. (2013) indicaron que analizar cada ácido en forma individual no es suficiente para determinar su efecto nutraceútico. Por lo tanto, es importante considerar la relación entre otros AG. En forma general, la reducción en la relación entre el ácido linoleico/ linolénico en las dietas en humanos favorece la salud y reduce el riesgo de presentación de enfermedades (Gómez et al., 2011). Por ejemplo, la relación entre el ácido linoleico/linolénico en los alimentos debería estar en un valor cercano a 4 para la prevención de enfermedades cardiovasculares, o en un valor de 2,5 para reducir la proliferación celular rectal en pacientes con cáncer (Simopoulus, 2002). Desde este punto de vista, en el presente estudio la leche producida con los cultivares Tanzania y Toledo, también ofrecería efectos benéficos sobre la salud humana por su baja relación linoleico/linolénico (Tanzania: 1,3 y Toledo: 1,4). 


\section{Conclusiones}

La alimentación de vacas gyr x pardo suizo con los pastos Tanzania y Toledo, resultó en una mayor concentración de ácidos grasos insaturados y de ALC (c9 t11) en la grasa láctea, en comparación con aquellas que consumieron pasto Mulato II, lo cual se explicó por un mayor aporte de ácido linolénico. Los mayores contenidos de estos AG (polinsaturados y ácido linoleico conjugado) en la grasa láctea, sugieren que la leche producida en estos cultivares podría ser más saludable en comparación con la leche producida con el pasto Mulato II.

El efecto del tercio de lactancia no fue consistente sobre el perfil de AG en la grasa de la leche. La concentración de ácido linoleico conjugado (c9 t11) en la grasa de la leche fue similar en las vacas en los diferentes tercios de lactancia.

\section{Agradecimientos}

Los autores expresan agradecimiento a la Corporación Colombiana de Investigación Agropecuaria (AGROSAVIA), por financiar este estudio.

\section{Literatura citada}

Allen, M.S. 2000. Effects of diet on short-term regulation of feed intake by lactating dairy cattle. J Dairy Sci. 83:1598-1624. doi:10.3168/jds.S0022-0302(00)75030-2

Amezquita, M. 1999. Diseño y análisis de ensayos para evaluación de pasturas en fincas. $7^{\text {ma }}$ Reunión del Comité Asesor de la RIEPT. CIAT, COL http://ciat-library.ciat.cgiar.org/forrajes_tropicales/pdf/4th/DisenoYanalisisDeEnsayos.pdf (consultado 15 ene. 2018).

AOAC (Association Official of Analytical Chemistry). 2010. Official methods of analysis of AOAC International. $18^{\text {th }}$ ed. AOAC Int., MD, USA.

Argel, J., W. Miles, D. Guiot, H. Cuadrado, y C. Lascano. 2007. Cultivar Mulato II (Brachiaria híbrido CIAT 36087): gramínea de alta calidad y producción forrajera, resistente a salivazo y adaptada a suelos tropicales ácidos bien drenados. CIAT, Cali, COL.

Bas, P., H. Archimede, A. Rouzeau, and D. Sauvant. 2003. Fatty acid composition of mixed-rumen bacteria: Effect of concentration and type of forage. J. Dairy Sci. 86:2940-2948. doi:10.3168/jds.S0022-0302(03)73891-0

Benjamin, S., and F. Spener. 2009. Conjugated linoleic acids as functional food: an insight into their health benefits. Nutr. Metab. 6:36. doi:10.1186/1743-7075-6-36

Bessa, R.J.B., J. Silva, J.M.R. Ribeiro, and A.B. Portugal. 2000. Retículo rumen biohydrogenation and the enrichment of ruminant edible products with linoleic acid conjugated isomers. Livest. Prod. Sci. 63:201-211. doi:10.1016/S03016226(99)00117-7

Bhattacharya, A., J. Banu, M. Rahman, J. Causey, and G. Fernandes. 2006. Biological effects of conjugated linoleic acids in helath and disease. J. Nutr. Biochem. 17:789-810. doi:10.1016/j.jnutbio.2006.02.009

Bilal, G., R. Cue, A. Mustafa, and J. Hayes. 2014. Effects of parity, age at calving and stage of lactation on fatty acid composition of milk Canadian Holsteins. Can. J. Anim. Sci. 94:401-406. doi:10.4141/cjas2013-172

Boufaied, H., P.Y. Chouinard, G.F. Tremblay, H.V. Petit, R. Michaud, and G. Belanger. 2003. Fatty acids in forages. I. Factors affecting concentrations. Can. J. Anim. Sci. 83:501-511. doi:10.4141/A02-098 
Bunout, D., y E. Escobar. 2000. Prevención de enfermedades cardiovasculares: ¿Deben aplicarse los mismos criterios en América Latina que en Europa y Norte América? Rev. Esp. Cardiol. 53:889-895. doi:10.1016/S0300-8932(00)75171-2

Chilliard, Y., and A. Ferlay. 2004. Dietary lipids and forages interactions on cow and goat milk fatty acid composition and sensory properties. Reprod. Nutr. Dev. 44:467-492. doi:10.1051/rnd:2004052

Corl, B., L. Baumgard, D. Dwyer, J. Griinari. B. Phillips, and D. Bauman. 2001. The role delta 9 desaturase in the production of cis-9 trans-11 CLA. J. Nutr. Biochem. 12:622-630. doi:10.1016/S0955-2863(01)00180-2

CORPOICA (Corporación Colombiana de Investigación Agropecuaria). 2002. Atlas de los sistemas de producción bovina. Módulo Región Caribe. Plan de Modernización Tecnológica de la Ganadería Bovina. CORPOICA, Bogotá, COL.

CORPOICA (Corporación Colombiana de Investigación Agropecuaria). 2013. Informe anual proyectos de investigación en pastos y forrajes. CORPOICA, Bogotá, COL.

Díaz, G.G., R. Gutiérrez, N. Pérez, S. Vega, S. León, M. González, G. Prado, G. Urbán, A. Ramírez, y M. Pinto. 2002. Detección de adulteraciones en la grasa de leche pasteurizada mexicana. Rev. Salud Anim. 24(1):54-59.

Dilzer, A., and Y. Park. 2012. Implication of conjugated linoleic acid (CLA) in human health. Crit. Rev. Food Sci. Nutr. 52(6):488-513. doi:10.1080/10408398.2010.501409

Dohme, F., A. Machmuller, F. Sutter, and M. Kreuzer. 2004. Digestive and metabolic utilization of lauric, myristic and stearic acid in cows, and associated effects on milk fat quality. Arch. Anim. Nutr. 58(2):99-116. doi:10.1080/00039420410001 667485

Doreau, M., and Y. Chilliard. 1997. Digestion and metabolism of dietary fat in farm animals. Br. J. Nutr. 78(1):15-35. doi:10.1079/BJN19970132

Elgersma, A., G. Ellen, H. Van Der Horst, H. Boer, P. Dekker, and S. Tamminga. 2004. Quick changes in milk fat composition from cows after transition from fress grass to a silage diet. Anim. Feed Sci. Technol. 117(1-2):13-27. doi:10.1016/j. anifeedsci.2004.08.003

Escobar, A., y J. Carulla. 2003. Efecto de la oferta de forraje sobre los parámetros productivos y composicionales de la leche en la sabana de Bogotá. Rev. Colom. Cienc. Pecu. 16:2721-2732. doi:10.21897/rmvz.273

Fawcet, B., and J.E. Scott. 1960. A rapid and precise method for determination of urea. J. Clin. Path. 13:156-159.

FEDEGAN (Federación de Ganaderos de Colombia). 2018. Consumo aparente per cápita anual de leche. Fondo estabilización de precios. FEDEGAN, COL. http://www.fedegan.org.co/estadisticas/consumo-0 (consultado 15 ene. 2018).

Gagliostro, G., A. Rodríguez, P. Pellegrini, P. Gatti, G. Musset, R. Castañeda, A. Colombo, y Y. Chilliard. 2006. Efectos del suministro de aceite de pescado sólo o en combinación con aceite de girasol sobre las concentraciones de ácido linoleico conjugado (CLA) y omega 3 (n-3) en leche de cabra. Rev. Arg. Prod. Anim. 26(2):71-87.

Garcés, R., and M. Mancha. 1993. One step lipid extraction and fatty acid methyl esters preparation from fresh plant tissue. Anal. Biochem. 211:139-143. doi:10.1006/abio.1993.1244

Gastón, A.C., M.L. Pabón, and J.E. Carulla. 2014. Concentration of trans-vaccenic and rumenic acids in the milk from grazing cows supplemented with palm oil, rice bran or whole cottonseed. R. Bras. Zootec. 43(6):315-326. doi:10.1590/S151635982014000600006

Glasser, F., Ferlay A., Doreau M., Schmidely P., Sauvant D., and Chilliard Y. 2008. Long chain fatty acid metabolism in dairy cows: a meta-analisys of milk fatty acid yield in relation to duodenal flows and de novo synthesis. J. Dairy Sci. 91:27712785. doi:10.3168/jds.2007-0383. 
Gómez, C., L. Bermejo, and V. Loria. 2011. Importance of a balance omega 6/omega 3 ratio for the maintenance of health: nutritional recommendations. Nutr. Hosp. 26:323-329. doi:10.1590/S0212-16112011000200013

Griinari, J.M., B.A. Corl, S.H. Lacy, P.Y. Chouinard, and K.V.V. Nurmela. 2000. Conjugated linoleic acid is synthesized endogenously in lactating dairy cows by delta 9 desaturase. J. Nutr. 130:2285-2291. doi:10.1093/jn/130.9.2285

Haeiwa, H., T. Fujita, Y. Saitoh, and N. Miwa. 2014. Oleic acid promotes adaptability against oxidative stress in 3T3-L1 cells through lipohormesis. Mol. Cell. Biochem. 386:73-83. doi:10.1007/s11010-013-1846-9

Harvatine, K.J., Y.R. Boisclair, and D.E. Bauman. 2009. Recents advances in the regulation of mill fat synthesis. Animal 3:4054. doi:10.1017/S1751731108003133

Hurley, W.L., G.J. Warner, and R.R. Grummer. 1987. Changes in triglyceride fatty acid composition of mammary secretions during involution. J. Dairy Sci. 70:2406-2410. doi:10.3168/jds.S0022-0302(87)80302-8

Huth, P., and K. Park. 2012. Influence of dairy product and milk fat consumption on cardiovascular disease risk: A review of the evidence. Adv. Nutr. 3:266-285. doi:10.3945/an.112.002030

Jeffery, H.J. 1970. The length of change-over periods in change-over designs with grazing cattle. Austr. J. Exp. Agric. Anim. Husb. 10:691-693. doi:10.1071/EA9700691

Jutzeler, R., and P. Colombani. 2010. Grass-based ruminant production methods and human bioconversion of vaccenic acid and estimations of maximal dietary intake of conjugated linoleic acids. Int. Dairy J. 20:433-448. doi:10.1016/j. idairyj.2010.01.008

Kay, J.K., W.J. Weber, C.E. Moore, D.E. Bauman, and L.B. Hansen. 2005. Effects of week of lactation and genetic selection for milk yield on milk fatty acid composition in Holstein cows. J. Dairy Sci. 83:3886-3893. doi:10.3168/jds.S00220302(05)73074-5

Kelly, M.L., J.R. Belly, D.A. Dwyer, J.M. Griinari, P.Y. Chouinard, M.E. Van-Amburgh, and D.E. Bauman. 2008. Dietary fatty acid sources affect conjugated linoleic acid concentrations in milk from lactating dairy cows. J. Nutr. 128:881-885. doi:10.1093/jn/128.5.881

Kgwatalala, P.M., E.M. Ibeagua-Awemu, A.F. Mustafa, and X. Zhao. 2009. Influence of stearoil-coenzime A desaturase 1 genotipe and stage of lactation on fatty acid composition of Canadian Jersey cows. J. Dairy Sci. 92:1220-1228. doi: $10.3168 /$ jds.2008-1471

Khan, N.A., N.W. Farooq, M. ALI, M. Suleman, N. Ahmad, S.M. Sulaiman, N.W. Cone, and W.H. Hendriks. 2015. Effect of species and harvest maturity on the fatty acids profile of tropical forages. J. Anim. Plant Sci. 25:739-746.

Kratz, M., T. Baars, and S. Guyenet. 2013. The relationship between high-fat dairy consumption and obesity, cardiovascular, and metabolic disease. Eur. J. Nutr. 52:1-24. doi:10.1007/s00394-012-0418-1

León, C.J.M. 2011. Efecto de la incorporación de leguminosas en pasturas de trópico alto sobre el contenido de ácido linoleico conjugado ALC en la leche. Tesis MSc., Universidad Nacional de Colombia, Bogotá, COL.

Lock, A., C. Preseault, J. Rico, K. DeLand, and M. Allen. 2013. Feeding a C16:0-enriched fat supplement increased the yield of milk and improved conversion of feed to milk. J. Dairy Sci. 96:6650-6659. doi:10.3168/jds.2013-6892

López, E. 2010. Health effects of oleic acid and long chain omega-3 fatty acids /EPA and DHA) enriched milks. A review of intervention studies. Pharmacol. Res. 61:200-207. doi:10.1016/j.phrs.2009.10.007

Mahecha, L., J. Angulo, B. Salazar, M. Cerón, J. Gallo, C.H. Molina, E.J. Molina, J.H. Suárez, J.J. Lopera, and M. Olivera. 2008. Supplementation with bypass fat in silvopastoral systems diminishes the ratio of milk saturated/unsaturated fatty acids. Trop. Anim. Health Prod. 40:209-216. doi:10.1007/s11250-007-9082-5 
Mendoza, C., M. Pabón, y F. Carulla. 2011. Variaciones diarias de la oferta forrajera, efecto sobre la producción y calidad de la leche. Rev. MVZ Córdoba 16:2721-2732. doi:10.21897/rmvz.273

Micha, R., and D. Mozzafrarian. 2010. Saturated fat and cardiometabolic risk factors, coronary heart desease, stroke and diabetes: a fresh look at the evidence. Lipids 45:893-905. doi:10.1007/s11745-010-3393-4

Mojica, J.E., E. Castro, J. Carulla, y C. Lascano. 2017. Efecto de la edad de rebrote sobre el perfil de ácidos grasos en gramíneas tropicales. Corpoica Cienc. Tecnol. Agropecu. 18:217-232.doi:10.21930/rcta.vol18_num2_art:623

Mojica, J.E., E. Castro, J. León, E. Cárdenas, M.L. Pabón, y J.E. Carulla. 2009. Efecto de la oferta de pasto kikuyo (Pennisetum clandestinum) sobre la producción y calidad composicional de la leche bovina. Livest. Res. Rural Dev. 21(1). http://www. lrrd.org/lrrd21/1/moji21001.htm (consultado 15 ene. 2018).

Mojica, R.J.E., R.E. Castro, Z.J. Silva, H.C. Hanzel, y Q.L. García. 2013. Producción y calidad composicional de la leche en ganaderías doble propósito del departamento del Cesar. CORPOICA, Cesar, COL. doi:10.21930/978-958-740-164-6

Mosley, E.E., B. Shaffi, P. Moate, and M. McGuire. 2006. Cis 9 Trans 11 Conjugated linoleic acid is synthesized directly from acid vaccenic acid in lactating dairy cattle. J. Nutr. 136:570-575. doi:10.1093/jn/136.3.570

Mosquera, P., y C. Lascano. 1992. Producción de leche de vacas en pasturas de Brachiaria decumbens solo y con acceso controlado a bancos de proteína. Rev. Past. Trop. 14(1):2-10.

Mozzafrarian, D., R. Micha, and S. Wallace. 2010. Effects of coronary heart disease of increasing polyunsaturated fat in place of saturated fat: A systematic review and meta-analysis of randomized controlled trials. PLoS Med. 7(3):e1000252. doi:10.1371/journal.pmed.1000252

Ntambi, J., and M. Makoto. 2003. Recent insights into stearoyl-CoA desaturase-1. Curr. Opin. Lipidol. 14:255-261. doi:10.1097/01.mol.0000073502.41685.c7

Ørskov, E.R., F.D. Deb Howell, and F. Mould. 1980. The use of the nylon bag technique for the evaluation of feedstuffs. Trop. Anim. Prod. 5(3):295-213.

Ortega, R., J. Espinoza, E. Palacios, A. Palacios, O. Arjona, B. Murillo, y F. Rivera. 2013. Perfil de ácidos grasos en leche de vacas Chinampas (Bos taurus) alimentadas con forraje fresco de matorral sarcocaulescente o heno de alfalfa. Arch. Med. 45:45-51. doi:10.4067/S0301-732X2013000100008

Palmquist, D.L., A.D. Beaulieu, and D.M. Barbano. 1993. Feed and animal factors influencing milk fat composition. J. Dairy Sci. 76:1753-1771. doi:10.3168/jds.S0022-0302(93)77508-6

Parales, J. 2015. Efecto de la suplementación de aceites vegetales y sus mezclas sobre la fermentación ruminal y el perfil de ácidos grasos en leche. Tesis MSc., Universidad Nacional de Colombia, Bogotá, COL.

Prieto-Manrique, E., J.E. Vargas-Sánchez, J. Ángulo-Arizala, y L. Mahecha-Ledesma. 2017. Aceites vegetales sobre ácidos grasos y producción de metano in vitro en vacas lecheras. Agron. Mesoam. 28:1-18. doi:10.15517/am.v28i1.22034

Rego, O., A. Cabrita, H. Rosa, S. Anes, V. Duarte, A. Fonseca, C. Vouzela, F. Rocha, and R. Bessa. 2016. Changes in milk production and milk fatty acid composition of cows switched from pasture to a total mixed ration diet and back to pasture. Ital. J. Anim. Sci. 15:76-86. doi:10.1080/1828051X.2016.1141330

Rico, D.E. 2013. Recovery of normal ruminal biohydrogenation and the novo fatty acid synthesis following induction of milk fat depression in dairy cows. Ph.D. Diss., The Pennsylvania State University, PA, USA.

Rico, J.E., B. Moreno, M.L. Pabón, y J. Carulla. 2007. Composición de la grasa láctea de la sabana de Bogotá con énfasis en ácido ruménico - CLA cis-9, trans-11. Rev. Colomb. Cienc. Pecu. 20(1):30-39. 
Roncallo, F.B., J. Barros, R. Bonilla, J. Murillo, y R. Del-Toro. 2009. Evaluación de arreglos silvopastoriles en explotaciones ganaderas de la microrregión bajo Magdalena. Corpoica Cienc. Tecnol. Agropecu. 10(1):60-69. doi:10.21930/rcta. vol10_num1_art:130

SAS. 2011. SAS/STAT, Software Versión 9.3. SAS Institute Inc., Cary, NC, USA.

Scerra, M., L. Chies, P. Caparra, C. Cilione, and F. Foti. 2016. Effect of only pasture on fatty acid composition of cow milk and Ciminà Caciocavallo Cheese. J. Food Res. 5(3):20-28. doi:10.5539/jfr.v5n3p20.

Shingfield, K.J., M. Bonnet, and N.D. Scollan. 2013. Recent developments in altering the fatty acid composition of ruminantderived foods. Animal. 7:132-162. doi:10.1017/S1751731112001681

Schmidely, P., F. Glasser, M. Doreau, and D. Sauvant. 2008. Digestion of fatty acids in ruminants: a meta-analysis of flows and variation factors. 1. Total fatty acids. Animal 2:677-690. doi:10.1017/S1751731108001717

Schroeder, G.F., G.A. Gagliostro, F. Bargo, J.E. Delahoy, and L.D. Muller. 2004. Effects of fat supplementation on milk production and composition by dairy cows on pasture: a review. Livest. Prod. Sci. 86:1-18. doi:10.1016/S03016226(03)00118-0

Simopoulos, A. 2002. The importance of the ratio of omega-6/omega-3 essential fatty acids. Biomed. Pharmacother. 56(8):365379. doi:10.1016/S0753-3322(02)00253-6

Siri, P., Q. Sin, F. Hu, and R. Krauss. 2010. Meta-analysis of prospective cohort studies evaluating the association of saturated fat with cardiovascular disease. Am. J. Clin. Nutr. 91:535-546. doi:10.3945/ajcn.2009.27725

Smit, L., A. Baylin, and H. Campos. 2015. Conjugated linoleic acid in adipose tissue and risk of myocardial infarction. Am. J. Clin. Nutr. 92:34-40. doi:10.3945/ajen.2010.29524

Soedamah-Muthu, S.S., E.L. Ding, W.K. Al-Delaimy, F.B. Hu, M.F. Engberink, W.C. Willett, and J.M. Geleijnse. 2011. Milk and dairy consumption and incidence of cardiovascular diseases and all-cause mortality: dose response meta-analysis of prospective cohort studies. Am. J. Clin. Nutr. 93:158-71. doi:10.3945/ajcn.2010.29866

Stoobs, T.H., and R.L. Sandland. 1972. The use of a latin square change - over design with dairy cows to detect differences in the quality of tropical pastures. Austr. J. Exp. Agric. Anim. Husb. 12:463-469. doi:10.1071/EA9720463

Stoop, W.M., H. Bovenhius, J.M.L. Heck, and J.A.M. Van-Arendock. 2009. Effect of lactation stage and energy status on milk fat composition of Holstein - Friesian cows. J. Dairy Sci. 92:1469-1478. doi:10.3168/jds.2008-1468

Toledo, J.M., and R. Schultze-Kraft. 1982. Metodología para la evaluación agronómica de pastos tropicales. CIAT, Cali, COL.

Ulbricht, T.L.V., and D.A.T. Southgate. 1991. Coronary heart disease: seven dietary factors. Lancet. 338:985-992. doi:10.1016/0140-6736(91)91846-M

Van-Soest, P.J., J. Roberton, and M. Lewis. 1991. Methods for dietary fiber, neutral fiber and no starch polysaccharides in relation to nutrition. J. Dairy Sci. 74:3583-3597. doi:10.3168/jds.S0022-0302(91)78551-2

Varádyová, Z., S. Kisidayova, P. Siroka, and D. Jalc. 2008. Comparison of fatty acid composition of bacterial and protozoal fractions in rumen fluid of sheep fed diet supplemented with sunflower, rapeseed and linseed oils. Anim. Feed Sci. Technol. 144:44-54. doi:10.1016/j.anifeedsci.2007.09.033

Yamasaki, M., K. Kishihara, I. Ikeda, M. Sugano, and K. Yamada. 1999. A recommended esterification method for gas chromatographic measurement of conjugated linoleic acid. J. Am. Oil Chem. Soc. 76:933-938. doi:10.1007/s11746-9990109-0 